\title{
CERVANTES, CONSTANTINOPLA Y LA GRAN SULTANA
}

Cinco años y medio fue cautivo Cervantes en Argel y la huella del cautiverio quedó bien marcada en su vida (alli «aprendió a tener paciencia de las adversidades" ${ }^{1}$ dice de sí mismo), como esa huella con frecuencia aparecerá en su obra ${ }^{2}$. Y no

1 En el «Prólogo al lector» de las Novelas ejemplares. Madrid, 1613.

2 Para la biografía cervantina, vid. Jean Canavaggio, Cervantes. Traducción de Mauro Armiño. Madrid, Espasa-Calpe, 1987, y RosA Rossi, Escuchar a Cervantes. Un ensayo biográfico. Valladolid, Ambito, 1988. Sobre aspectos biográficos del cautiverio y la huella del mismo en la literatura cervantina, vid. F. CoRTines MURUBE, -Cervantes en Argel y sus libertadores trinitarios», en Boletín de la Biblioteca Menéndez Pelayo, XXIII, 1947, 87-100; J. M. ALDA TESAN, «Los cautivos de Cervantes» en Boletín de la Real Academia Española, XXVII, 1947-1948, 245-339; Alonso ZAMORA VICENTE, «El cautiverio en la obra cervantina”, en Homenaje a Cervantes. Ed. de F. Sánchez Castañer. Valencia, Mediterráneo, 1950, II, 457-504; LuIs RosALes, Cervantes y la libertad. Madrid, 1959-1960; J. B. Avalle-ArCe, «La captura de Cervantes, en Boletín de la Real Academia Española, XLVIII, 1968, 237-280. Reeditado con el título «La captura (Cervantes y la autobiografía)» en Nuevos deslindes cervantinos. Barcelona, Ariel, 1975, 277-333; del mismo en este volumen «El curioso y el capitán (Cervantes y la libertad artística)», 117-152; AlberTo SANCHEz, «Contraluz del cautiverio en la obra de Cervantes», en El Ingenioso Hidalgo, XXXV, 1972. Tirada aparte: Madrid, Publicaciones del Instituto Nacional de Bachillerato «Cervantesx, 1973; Grorge Camanis, Estudios sobre el cautiverio en el Siglo de Oro. Madrid, Gredos, 1977; Jean Canavaggio, aLe 'vrai' visage d'Agi Morato», en Les Langues Néo-latines (Hommoge a Louis Urrutia), 239, 1981, 23-38; del mismo, *Agi Morato, entre historia y ficción*, en Critica hispanica, DX, 1989, 17-22; WILluard KING, «Cervantes, el cautiverio y los renegados», Nueva Revista de Filología Hispánica, XI, 1, 1992, 279-291. Sobre los corsarios y el cautiverio desde la perspectiva histórica, vid. S. Bono, I corsari barbareschi. Torino, 1964 y F. Braudel, El Mediternaneo y el mundo mediterraneo. México, FCE, 1976. 
deja de ser curioso un dato: el personaje histórico que más veces menciona Cervantes en su producción literaria es Mahoma ${ }^{3}$.

Ateniéndonos a las obras que, en parte o en todo, tienen como motivo el cautiverio, obligado es recordar, siguiendo un criterio cronológico de aparición de las mismas aunque dejando para el final el teatro, en primer lugar La Galatea. Efectivamente, en el Libro segundo de esta obra Silerio cuenta el ataque de unos piratas turcos a un pueblo de la costa catalana 4; más tarde, en el Libro quinto, Timbrio se dirige desde a Italia a España, en compañía de Nísida y Blanca, con las cuales se casarán finalmente Silerio y él mismo. La nave es atacada por quince bajeles turcos, al mando de Arnaute Mami, nombre del renegado albanés que capturó a Cervantes también en el momento que volvía de Italia a España. Cuando los cristianos son llevados hacia Argel, una tormenta consigue desviar los bajeles de su ruta y son arrojados precisamente a las playas de Cataluña, convirtiéndose los corsarios en cautivos y en hombres libres los cristianos ${ }^{5}$.

Por lo que se refiere al Quijote, son los capítulos XXXIX al XLI de la Primera parte los que nos interesan. Aqui, inmediatamente después del discurso de las armas y las letras, Ruy Pérez de Viedma cuenta su historia en «tierra de moros» de donde acaba de llegar en compañía de una mujer vestida de morisca. Este relato del «capitán cautivo», por el cual se ha llegado a considerar a Cervantes el creador de la novela histórica contemporánea ${ }^{6}$, contiene no po-

\footnotetext{
${ }^{3}$ Apud Alberto SAnchez, «Contraluz del cautiverio...», cit., p. 3.

- Ed. de Juan Bautista Avalle-Arce. Madrid, Espasa-Calpe, Col. «Clásicos Castellanosx, pp. 170 y ss.

3 Edición citada, pp. 350 y ss. Vid. Alberto SAnchez, «Historia de Timbrio y Silerio», en Anales cervantinos, II, 1952, 457-504; JuAN BaUtista Avalle-ARCE, «El cuento de los dos amigos (Cervantes y la tradición literaria. Primera perspectiva)», en Nuevos deslindes cervantinos, cit., 153-211, especialmente 182-192. Versión modificada del trabajo publicado antes en Nueva Revista de Filologia Hispanica, Xl, con el título «Una tradición literaria: el cuento de los dos amigos»; JoAOUIN DiAz Ferruz, «Vacilaciones y contradicciones en la 'Historia de Timbrio y Silerio'. Aspectos sobre la composición de La Galatea de Miguel de Cervantes», Glosa, 1989, 1, 119-134.

- E. GonzAlpz LOPEz, «Cervantes, maestro de la novela histórica contemporáneax, en Homenaje a Casalduero. Madrid, Gredos, 1972, 179-187. Vid., sobre este episodio, Francisco Marouez Vnunveva, Personajes y temas del «Quijote». Madrid, Taurus, 1975, 92-146; MAXame CHevalrer, «El cautivo entre cuento y novelax. Nueva Revista de Filologia Hispdnica, XXXII, 1983, 403-411; Marita Caterina RUTA, «Zoraida, los signos del silencio en un personaje cervantino», en Anales cervantinos, XXI, 1983, 119-133; LuIs ANDRÉs MURILlo, «El Ur-Quijote, nueva hipótesis», Cenvantes, I, Fall, 43-50; Gustavo InLDEs, El discurso critico de Cervantes en ael cautivow. México, Universidad Nacional Autónoma, 1990; ANA L. BAOUERO EscudERO, *Tres historias intercaladas y tres puntos de vista distintos en el primer Quijote» en Actas del II Coloquio intemacional de la Asociacion de cervantistas. Bance-
} 
cos elementos autobiográficos, como también existen en él bastantes otros que podemos encontrar en obras diferentes cervantinas y siendo, incluso, una buena parte de esta historia la misma que Cervantes desarrollará dramáticamente en Los baños de Argel.

En cuanto a las «Novelas ejemplares», dos son las que se relacionan con el cautiverio cervantino. Por una parte, El amante liberal, cuyos protagonistas son apresados por los turcos en Trápani y llevados a Chipre, aunque conseguirán luego la libertad. Es ésta una novela plena de recuerdos del cautiverio, con aventuras marítimas, descripción de la vida de los turcos, por cierto realizada sin acritud, etc., y en la cual el amo chipriota del protagonista es Hasán Bajá, el mismo nombre del renegado que fue dueño de Cervantes en Argel y que también aparece en El trato de Argel, en el Quijote y en Los baños de Argel. Por cierto, que en esta novela figuran unos versos, los únicos que hay en la misma, y que son iguales a otros de Los baños de Argel. La segunda novelita es La española inglesa; efectivamente, en la segunda mitad del relato se cuentan las aventuras de Ricaredo, su ataque a las galeras de, otra vez, Arnaute Mami, apareciendo en ella diversos datos con seguridad autobiográficos cervantinos... ${ }^{7}$.

También en el Persiles hay recuerdos de esta etapa de nuestro escritor; en el Libro tercero, capítulos X y XI, se cuenta el ataque a las costas valencianas por 16 bajeles de corsarios, los cuales entran a saco en las casas de los cristianos, llevándose todo lo que hay de valor y huyendo en compaña de los moriscos del lugar ${ }^{8}$.

En fin, por lo que se refiere al teatro, cuatro son las comedias que tienen como motivos fundamentales el cautiverio cervantino y el mundo morisco o turco: El trato de Argel, Los baños de Argel, El gallardo español y La Gran Sultana. A las dos primeras se le ha dedicado especial atención por parte de la crítica; la bibliografía de las dos últimas, por el contrario, es menor, aunque en los últimos

lona, Anthropos, 1991, 417-423; ALICI PARODI, «El episodio del cautivo, poetica del Quijote: versímiles transgredidos y diálogo para la construcción de una alegoriax en idem, 433-441.

7 Además de los estudios generales sobre las Novelas ejemplares de Amezóa, Casaldurro, El Saffar, Osterc, la puesta a punto de Petre N. Dunn en Suma cervantina, y el libro colectivo Cervantes's aExemplary Novels» and the Adventure of Writing. Ed. Michael Nerllich and Michael Spadaccini. Minneapolis, Prisma Institute, 1990, vid., más especificamente, el ya clásico estudio de don RAFAzi LAPESA «En torno a La española inglesa y el Persiles» en Homenaje a Cervantes..., cit.; DAvid ClufF, *The Structure and Theme of La espanola inglesa: a reconsideration*, Revista de Estudios Hispanicos, 4, 1976, 262-281.

' Ed. de J. B. Avalle-Arce. Madrid, Castalia, 1969, pp. 342 y ss. Vid. también DuNA DE ARMAs Wilson, Allegories of love. Cervantes's Persiles and Sigismunda. Princeton University Press, 1991. 
años estudios de carácter general y algunos más específicos han paliado esa escasez ${ }^{9}$.

De todas estas obras, La Gran Sultana nunca se estrenó y el acercamiento desde el campo de la crítica académica e investigadora ha sido mínimo e incluso en muchos casos de carácter negativo ${ }^{10}$, cuando no escasamente convincente desde los mismos planteamientos ". Una afirmación, sin embargo, es necesaria desde el principio: La Gran Sultana es una obra «rara» o mejor, como López Estrada ha escrito, «peregrina» en el sentido cervantino de la palabra como «extrañaw, y ello, decimos nosotros, por varias razones. En primer lugar, porque, frente al desarrollo tópico de las obras cervantinas de cautiverio (captura de los protagonistas, estancia en Berbería de esos personajes como cautivos y vuelta a la libertad o muerte del cautivo), La Gran Sultana se refiere a una cristiana que llega a ser Sultana, que provoca a lo largo de la obra con sus oraciones, su cruz al cuello, su rosario en la mano, su vestido «a la cristianax, su actitud ante el Sultán, la ayuda que presta al resto de los cautivos... En segundo lugar, el marco en que se desarrolla

- Sobre el teatro cervantino obligado es citar, como obra de conjunto, el excelente libro de Jean Canavaggio, Cenvantes dramaturgue. Un théatre d naître. Paris, PUF, 1977, recordando también los ya clásicos de Cotarelo, Marrast, Casalduero, la puesta a punto de WARDROPPER y ASENSIo en Suma cervantina y Friedman. Para artículos o artículos de carácter más específico sobre las obras de cautiverio, vid. la bibliografía que ofrece la reciente edición de Canavaggio de Los baños de Argel y Pedro de Urdemalas (Madrid, Taurus, 1992), la cual puede completarse con la que recoge regularmente ALBERTo SANCHEZ en Anales cenvantinos (último volumen XXXI, 1993). Sobre La Gran Sultana, vid. recientemente los trabajos de PAUL LEWIS SMrrt, aLa gran sultana Doña Catalina de Oviedo: A Cervantes Practical Jokex, en Forum for Modern Language Studies, 1981, 68-82; Jean Canavaggio, aSobre lo comico en el teatro cervantino: Tristán y Madrigal, bufones in partibus», en Nueva Revista de Filologia Hispánica, XXXIV, 1985-86, 538-547, publicado también en lo que se refiere a Madrigal en Cuadernos de Teatro Clásico, 7, 1993, 47-53; Francisco LOPEZ EsTrADA, «Vista a Oriente; la española en Constantinoplax, en idem, 3146; Stanislav Zimic, El teatro de Cervantes. Madrid, Castalia, 1993, pp. 183-203.

${ }^{10}$ Quizás el juicio más radicalmente negativo es el de Francisco YNDURAin en su «Estudio preliminar* a Obras dramáticas de Cervantes. Madrid, BAE, 1962. De xopera buffa” fue calificada por Schevill y Bonilla y este carácter cómico es el que han subrayado la mayor parte de los críticos posteriores. Discutible es para Albert Mas su interés dramático $(I, 349)$. Cotarelo (El teatro de Cervantes...) afirmaba que era una de las mejores comedias de Cervantes y los juicios de Canavaggio, López Estrada y Zimic son de sumo interés por ir más allá del plano de la comicidad.

${ }^{11}$ Es el caso de Jonoutn Casalduero, Sentido y forma del teatro de Cervantes (Madrid, Gredos, 1966), para quien la significación de tipo religioso es el elemento que el del pecado originaly, lo cual nos parece excesivamente reducionista. De todas maneras, la interpretación del teatro cervantino, como la del resto de la producción de nuestro autor, se sitúa en la concepción que de Barroco igual a Contrarreforma tenía el profesor Casalduero. 
la historia que se cuenta no es Argel sino un espacio específico y diferente -Constantinopla-, lugar lejano y exótico para el español de la época. Pero, si esa Turquía es un elemento exótico no es, sin embargo, algo completamente ajeno a las preocupaciones de la Europa y naturalmente de la España de entonces ${ }^{12}$, de la misma manera que los dos tomos ya consagrados por Albert Mas a la presencia del «tema turco» en nuestra literatura áurea ${ }^{13}$ demostraron, hace más de veinticinco años, lo que era patente y había sido motivo de estudios de menor envergadura: la gran riqueza de obras con Turquía, y especialmente con Constantinopla, como centro de atención y la moda de que gozara, especialmente durante la segunda mitad del XVI y primera del XVI, todo lo relacionado con lo turco $^{14}$. Un testimonio y bien significativo, ya que nos movemos en el campo de la literatura dramática, es Lope de Vega. Albert Mas, que recuerda obras de Lope según ale role plus ou moins important que chacune d'elles accorde aux turcs», afirma que nueve desarrollan un episodio turco importante fuera de Berbería, ocho lo desarrollan en Berbería, diez obras tienen personajes turcos episódicos y en siete hay alusiones a turcos ${ }^{15}$. Todo esto completa naturalmente otras muchas referencias y especialmente las habituales y tópicas en este campo: el Viaje de Turquía y la literatura nacida en torno a Lepanto (recordemos, cervantinamente, Don Quijote, II, 1).

Pero vuelvo a La Gran Sultana y lo hago, por ahora, sin apartarme de Albert Mas, pues la última parte de su estudio me parece metodológicamente hoy todavía muy válida para mis propósitos. Según Mas, en las obras literarias por él estudiadas hay, por una parte, unas constantes ideológicas (el poder turco, la dignidad imperial española, la exaltación de la fe católica, el desprecio por el Islam, el retrato propagandísticamente negativo de los turcos...) y hay, por otra, unas convenciones literarias que para Mas son tres fundamentalmente: el cautiverio, el amor y el exotismo ${ }^{16}$. Aunque hago referencias a lo segundo y esté presente continuamente lo primero, mi intención (y recordamos los términos «raro» y «peregrino» antes citados) es detenerme en Constantinopla, en el papel que como lugar exótico jugaba para los contemporáneos de Cervan-

12 Vid., como trabajo reciente y muy útil, el de RICARDo GARCin CARCEL incluido en la Actas de las XVI Jornadas de teatro clásico de Almagro, bajo el título «La psicosis del turco en los españoles del Siglo de Oro» (en prensa).

${ }^{13}$ Albert MAS, Les turcs dans la litterature espagnole du Siecle d'Or. Paris, Centre de Recherches Hispanique, Institute d'Etudes Hispaniques, 1967, 2 vols.

14 Mas, 1, 505-528.

15 I, 389.

16 II, 149 y ss. 
tes (ellos no habían estado en Argel cinco años y medio) y cómo el autor de La Gran Sultana lo lleva a su obra ${ }^{17}$.

El comienzo de la comedia es significativo para nuestros prop6sitos y ya desde la acotación que presenta el espacio y los personajes de la primera secuencia de la pieza:

Sale[n] SALEC, turco, y ROBERTO, vestido a lo griego, $y$, detrás dellos, un ALARABE vestido de un alquicel; tray en una lanza muchas estopas, y en una varilla de membrillo, en la punta, un papel como billete, y una velilla de cera encendida en la mano; este tal ALARABE se pone al lado del teatro, sin hablar palabra, y luego dice ROBERTO: ${ }^{18}$

Que un cristiano cautivo aparezca vestido «a lo griego» o «en hábito de griego» era habitual en Constantinopla y así se nos presentará también después Andrea. La descripción se completará con ese árabe (alárabe) vestido «de un alquicel» ${ }^{19}$, término que naturalmente proviene del árabe, y con la vara y el billete demandando al Sultán, como inmediatamente explicará Salec en los primeros versos de su intervención:

Roberto.

Mas ¿qué fantasma es ésta que se ofrece, coronada de estopas media lanza?

Alárabe en el traje me parece.

Salec. Tienen aqui los pobres esta usanza cuando alguno a pedir justicia viene: De una cafía y de estopas se previene, $y$ cuando el turco pasa enciende fuego, a cuyo resplandor él se detiene; pide justicia a voces, dale luego lugar la guarda, y el pobre, como jara, arremete turbado y sin sosiego, y en la punta y remate de una vara al gran señor su memorial presenta, que para aquel efecto el paso para.

Luego, a un bello garzón, que tiene cuenta con estos memoriales, se le entrega, que, en relación, después dellos da cuenta;

17 Complétese con Canavaggio, Cervantes dramaturgue..., cit., para las razones de la selección de Constantinopla como lugar de la acción de la obra, como asimismo para la posible influencia de la predilecciones literarias del momento y la relación de La Gran Sultana con las posibles fuentes históricas.

18 Miguel de Cervantes. Teatro completo. Ed. de Antonio Rey Hazas y Florencio Sevilla Arroyo. Barcelona, Planeta, 1987, p. 373.

19 «Tejido de lana, o de lino y algodón, de bastante anchura, hecho todo de una pieza, para diferentes usos; como para capas, sobremesas, cubiertas de bancos, mantas, etc. (Dic. Autoridades); "vestidura morisca a modo de capa" (Corominas). 
pero jamás el término se llega

del buen despacho destos miserables,

que el interés le turba y se le niega. (vv. 4-24)

Finalizada esta descripción, comenzará de nuevo otra escena de carácter ambiental con el mismo fin que tiene la anterior. Esta escena se abrirá con una acotación también de relativa riqueza, sobre todo si, como es sabido, comparamos este procedimiento con la escasez en su práctica por parte del resto de los dramaturgos de la época ${ }^{20}$. Dice así la acotación:

Entra a este instante el GRAN TURCO con mucho acompañamiento; delante de sí lleva un PAJE vestido a lo turquesco, con una flecha en la mano, levantada en alto, y detrás del TURCO van otros dos garzones con dos bolsas de terciopelo verde, donde ponen los papeles que el TURCO les da ${ }^{21 .}$

A partir de aquí se hará referencia a Santa Sofía, a la zalá o "ceremonia que hacen los moros, que vale tanto como hacer reverencia, venerar o adorar» (Covarmubias), al desfile del Gran Turco y su séquito - seis mil soldados a pie y a caballo-, hacia la Mezquita, al hecho de que ningún moro o turco pueda ver el rostro del Sultán... Con menos de cincuenta versos, Cervantes ha ofrecido un cuadro que la imaginación del lector puede completar adecuadamente, un cuadro que, naturalmente, tendría que ir acompanado de la pertinente escenografía con el fin de acentuar el exotismo de unos vestidos, de unos objetos, de una arquitectura, incluso del físico de unos personajes convertidos en «peregrinas» figuras para el espahol de aquel tiempo, aunque menos, claro está, que para la mayor parte de los europeos de entonces... Pero la obra cervantina no llegó a las tablas e, incluso, si hubiera llegado, ese color local, esa riqueza escenográfica que ha podido disfrutar el espectador de nuestro tiempo, habría tenido que suplirlo el auditorio del xvI con la reconstrucción del universo «turquesco» a través de la palabra de los personajes cervantinos. A ello favorecería y mucho la intervención de Roberto que, asombrado ante la escena presenciada y completada por la explicación de Salec, subraya:

Cosas he visto aquí que de admirables pueden al más gallardo entendimiento suspender. (vv. 25-27)

${ }^{20}$ No es muy positiva la opinión de Albert Mas al mencionar el uso -para el abuso- de las acotaciones cervantinas: «Une piece de Lope n'offre jamais autant de didascalies. Cervantes en abuse...* (Les turcs.., 1, 352).

21 Ed. cit., p. 374. 
Cosas que admiraba y suspendían el entendimiento de Roberto, pues, como bien testimonió A. Mas con no pocos textos y como ha resumido recientemente López Estrada, «lo que sucedía en La Gran Sultana no pertenecía al dominio del Islam que había sido español, y que tan metido estaba en la vida de la nación, sino que se radicaba en las puertas del Oriente lejano, del que emanaba la atracción que venían ejerciendo desde siglos las prodigiosas noticias que llegaban de China, la India y el Islam asiático, y que tenía su puerta de Europa en Constantinopla, la capital del Imperio de los turcos, en donde se sitúa el lugar en que ocurre la comedia de Cervantes. Espacio, pues, propicio para la maravilla, del que podían salir inesperados surtidores de sorpresas para el público del teatro. Su propósito fue escribir una comedia en la que los sucesos que aparecieran sobre las tablas propiciasen la exhibición de un gran espectáculo inusual. Si las palabras de los actores pretendía Cervantes que fuesen llenas de brillo e indudablemente chocantes, también convenía que su vestimenta fuese exótica y colorida, y que sonase de cuando en cuando una melopea oriental, en contraste con músicas y danzas españolas» 22.

Conocidos el espacio y el que será protagonista de la obra, sólo queda contar la historia que conducirá a la existencia de Catalina y a su presencia en Constantinopla y concretamente en el Palacio del Sultán. De esta manera, y aunque La Gran Sultana no es precisamente un prodigio de construcción dramática, la acción fundamental de la pieza ya puede ponerse en marcha, pues las referencias imprescindibles, y aún más que las imprescindibles, se han ofrecido al lector o espectador en esta prótasis o exposición de datos ${ }^{23}$.

$\mathrm{Si}$ hemos hecho referencia a las acotaciones de la primera secuencia de la obra por su excepcionalidad dentro de nuestro teatro áureo, nótese cómo Cervantes presenta el espacio en que se desarrollará la escena que merecerá nuestra atención en las páginas siguientes:

Parece el Gran Turco detrás de unas cortinas de tafetán verde; salen cuatro Bajaes ancianos; siéntanse sobre alfombras y almohadas; entra el EMBAJADOR de Persia, y al entrar le echan encima una ropa de brocado; llevanle dos turcos de brazo, habiéndole mirado primero si trae armas encubiertas; llévanle a asentar en una almohada de terciopelo; descúbrese la cortina: parece el GRAN TURCO: mientras esto se hace

\footnotetext{
22 „Vista a Oriente...*, cit, pp. 33-34.

${ }^{23}$ No es nuestra misión aquí destacar el significado que, a través de estas secuencias primeras, se deduce de la personalidad del Sultán, pero es evidente que en ellas hay algo más que color local o más o menos valiosos curdros de caracter costumbrista. Vid., últimamente, ZIMIC, El teatro de Cervantes, cit., pp. 186-187.
} 
puede[n] sonar chirimias. Sentados todos, dice el EMBAJADOR: ${ }^{24}$

Y lo que el Embajador dice es que ha llegado a la corte del Sultán para proponerle la paz entre su pueblo y el de Persia. El acuerdo, sin embargo, no se llevará a cabo y la causa es España, pues, como afirman los Bajaes, han sido frecuentes las visitas de embajadores persas a la corte del rey Felipe con el fin de proponer también la paz, traicionando así a los pueblos árabes. Las palabras de uno de los Bajaes son explícitas:

Ese cabeza roja, ese maldito,
que de las ceremonias de Mahoma,
con depravado y bárbaro apetito,
unas cosas despide y otras toma,
bien debe de pensar que el infinito
poder, que al mundo espanta, estrecha y doma,
del Gran Señor, el cielo tal le tenga,
que hacer paces infames le convenga.
Su mendiguez sabemos y sus manas,
por quien con el de nuevo me enemisto,
viendo que el grande rey de las Españas
muchos persianos en su corte ha visto.
Estas son de tus dueños las hazañas;
pedir favor a quien adora Cristo;
y como ve que el ayudarle niega,
por paz cobarde en ruego humilde ruega. ( $v$. 1026-1041)

Después de esta intervención, no es extraño que el Embajador sea expulsado de la presencia del Sultán, al mismo tiempo que se le califica con el peor insulto que puede recibir: «embajador cristianox, es decir traidor no sólo a su pueblo sino también a su fe.

${ }^{24}$ Otras acotaciones en la obra con parecida riqueza en pp. 431, 434, 435, 436... de la ed. citada. En la p. 431 leemos: Entranse, y la SULTANA se ha de vestir a lo cristiano, lo más bizarramente que pudiere. Salen los dos MUSICOS, y MADRIGAL con ellos, como cautivos, con sus almillas coloradas, calzones de lienzo blanco, borceguies negros, todo nuevo, con vueltas sin lechuguillas; MADRIGAL traiga unas sonajas, y los demás sus guitarras; sendalanse los músicos primero y segundo. No es momento de analizar como merece esta acotación, pero sl queremos hacer notar la precision cervantina, al advertir, por ejemplo, que vayan acon vueltas sin lechuguillas», es decir, sin ondas a manera de hoja de lechuga, quizá para evitar, como indica Covarrubias en su Diccionario, aque más parezcan hojas de lampaços que de lechugasn. La última amplia acotación de la obra (p. 456) anticipa los versos finales con música e intensas luces, que arropan esa apoteosis terminal de la pieza: Suenan las chirimias; comienzan a poner luminarlas; salen los GARzONES del TURCO por el tablado, corriendo con hachas y hachos encendidos, diciendo a voces: "Viva la gran sultana doria Catalina de Oviedo! ¡Feliz parto tenga, tenga parto feliz!» 
Como ya la crítica ha mencionado, otros dos aspectos de verdadera importancia habría que señalar en esta secuencia y que nosotros nos limitamos a recordar como complemento de este retablo que Cervantes ha puesto en escena; por una parte, las actitudes mantenidas por los Bajaes ante el problema que Turquía tiene planteado con Persia ${ }^{25}$ (paz/guerra, y las razones de una u otra opción); por otra parte, esa correspondencia que de la situación hace Cervantes al recordar lo que España ha vivido y vive en esos momentos:

\section{Bajá 2. Triste historia es la que leo;}

que a nosotros la Persia así nos daña,

que es lo mismo que Flandes para España. (vv. 1079-1081)

Y algo que estimamos sintomático de una actitud cervantina: este Bajá será el que inmediatamente, y de una manera muy práctica, defenderá la paz con Persia, mientras el otro recomendará ardientemente la guerra ${ }^{26}$.

Naturalmente que son muchos los momentos de La Gran Sultana en que podríamos todavía detenernos para mostrar esa Constantinopla que Cervantes imagina, aunque, tengámoslo siempre presente, desde la vivencia de unos acontecimientos y de unos lugares que no estaban tan lejos de su propia biografía y que completarán las informaciones orales y las lecturas de obras con el Oriente como protagonista ${ }^{27}$. Quiero, para acabar, referime precisamente a una

25 Durante los reinados de Murad o Amurates III (1574-1595), de su hijo Mehmed III (1595-1604) y de Ahmed I (1604-1617), las guerras con los persas fueron continuas, hasta 1618 en que Osmán II firma la paz con Persia. Vid., desde una perspectiva histórica, S. J. Sнаw, History of the Ottoman Empire and modem Turkey. Cambridge University Press, 1975-1977, dos vols.; J. P. Roux, Histoire des turcs. Paris, 1984; H. INALCIK, The Ottoman Empire. The Classical Age. 1300-1600. London, 1973.

26 . Cervantes hace, por tanto, que de una manera bien traída por los pelos la escena se ilumine de repente por este relámpago de actualidad política que podría sorprender. En todas partes se cuecen las guerras, y conviene - también en la escena- que haya de unos y de otros, de los que defienden los acuerdos pacíficos y de los que, siempre más fácilmente, justifican las guerras. De esta forma inesperada, Cervantes entremete la mención de la paz en un asunto tan espinoso como era el de las guerras de Flandes que acabó en la llamada tregua de los doce años en tiempos de Felipe III...» LÓPEz EsTRADA, «Vista a Oriente...», pp 36-37. Vid. también Mas y Canavaggio (Cervantes dramaturgue...) para completar el resumen de LOPEZ ESTRADA.

27 Albert mas (y Cannvaggio ha insistido adecuadamente en ello) ya se detuvo en demostrar que Cervantes no crea con La Gran Sultana una obra en la cual el asunto que en ella se desarrolla sea pura fantasia, producto de la imaginación del escritor. Partiendo de una afirmación de F. YNDURlin ( $\propto$ La historia de dona Catalina de Oviedo, favorita del Gran Turco, Murad I o Amurates, no tiene base real, 
de las secuencias finales de la comedia, una secuencia que tiene como protagonista a Madrigal en su diálogo con Andrea y, fundamentalmente, a la despedida que aquél hace de Constantinopla, momento culminante de la obra como de su lectura se deduce y - para la historia del arte escénico queda- también de la representación ${ }^{28}$ :

Madrigal.
te diré maravillas. Ven, que muero
por verme ya en Madrid hacer corrillos
de gente que pregunte: «Como es esto?
Diga, señor cautivo, por su vida:
¿es verdad que se llama la sultana
que hoy reina en la Turquía Catalina,
y que es cristiana, y tiene don y todo,
y que es de Oviedo el sobrenombre suyo?»
¡Oh! ¡Qué de cosas les diré! Y aun pienso,
pues tengo ya el camino medio andado,
siendo poeta, hacerme comediante
y componer la historia desta niña
sin discrepar de la verdad un punto,
representando el mismo personaje
allá que hago aquí. ¿Ya es barro, Andrea,
ver al mosqueterón tan boquiabierto,
que trague moscas, y aun avispas trague,
sin echarlo de ver, sólo por verme?
Mas él se vengará quizá poniéndome
nombres que me amohínen y fastidien.
¡Adiós, Constantinopla famosísima!
¡Pera y Permas, adiós! ¡Adiós, escala,
Chifutí, y aun Guedí! ! ¡Adiós, hermoso

y no sabemos cómo se fijó ni por qué conducto llegara a nuestro dramaturgo; el cual parece que creía en la autenticidad del suceso y por tal nos lo da en la comediax. Edición BAE, cit., p. 241), Mas documenta la existencia en la tradición y en las relaciones y otros documentos históricos de una cristiana que llega a ser Sultana en el reinado de Amurates III, hijo de Selim II, el gran derrotado en Lepanto (Mas, pp. 341-348). Lo que si hace Cervantes es convertir a esta cristiana en española y llamarla Catalina de Oviedo. A partir de aquí, la imaginación cervantina produce una comedia donde su sonrisa bañada de ironla late una vez más a través de situaciones plenas de humor, pero de un humor lleno de sutilezas, solapadas actitudes, cuando no situaciones de doble sentido, diálogos que saltan de la lírica amorosa casi pastoril a la fanfarronada y al disparate.

${ }^{28}$ Madrigal es el personaje que mayor atención ha suscitado en el público durante las representaciones de La Gran Sultana en el montaje realizado por la Compañía Nacional de Teatro Clásico y que se estrenó en el Teatro Lope de Vega de Sevilla el 6 de septiembre de 1992. El final de la secuencia que ahora comentamos ha merecido el aplauso en todas las funciones que se han llevado a cabo, a lo cual, bien es cierto, han contribuido los recursos escénicos puestos en práctica por el director de la obra, Adolfo Marsillach, y también por la excelente interpretación de Héctor Colomé en el papel de Madrigal. 
jardín de Visitax! ¡Adiós, gran templo

que de Santa Sofía sois llamado, puesto que ya servis de gran mezquita! ¡Tarazanas, adiós, que os lleve el diablo, porque podéis al agua cada día echar una galera fabricada desde la quilla al tope de la gavia, sin que le falta cosa necesaria

Andrea. a la navegación!

$\begin{array}{ll}\text { Madrigal. } & \begin{array}{l}\text { Madrigal. } \\ \text { Ya lo veo, y no me quedan } \\ \text { sino trescientas cosas a quien darles } \\ \text { el dulce adiós acostumbrado mío. }\end{array} \\ \text { Andrea. } & \text { Vamos, que tanto adiós es desvario. }\end{array}$

Mira que es hora,

(vv. 2904-2940)

Hermosísima tirada de versos, de la cual queremos destacar dos aspectos. El primero, aunque no se refiere directamente al tema objeto de este trabajo, es esa alusión a los mentideros madrileños - las gradas de San Felipe, la Puerta de Guadalajara....-, a los que, por otra parte, se refieren con frecuencia los escritores y los soldados vueltos de Flandes o Italia. Y, con esa referencia, de nuevo el «teatro en el teatro» ${ }^{29}$ con la promesa de componer una obra (obra que ya estamos viendo y escuchando) para ser representada en el Corral de la Cruz o en el del Príncipe acallando a los «mosqueterones*... ${ }^{30}$.

El segundo aspecto a destacar es, claro está, la despedida de Constantinopla y el tono con que Madrigal lo hace, pleno de admiración y de asombro ante los lugares que han enmarcado su vida reciente, un tono que llega incluso al afecto por la ciudad y a cierto dolor por la partida, lo cual naturalmente advierte Andrea cuando dice a su compañero: «Vamos, que tanto adiós es desvarío». Y es que, para nosotros, quizás la actitud cervantina ante el mundo oriental de cautiverio presentado (trasunto, claro, del argelino) tiene en este parlamento una expresión muy explícita: por una parte, todo ese elemento positivo citado; por otra, la constatación de una situación hostil y enemiga, lo cual se muestra perfectamente en la referencia a las atarazanas (asombro por el poder del turco al poder botar cada día una galera en ellas construidas), pero, al mismo

29 Vid, José Mureh Dizz Borque, *Teatro dentro del teatro, novela deniro de la novela en Miguel de Cervantes», en Anales cervantinos, XXI, 1972, 113-128, y JeAN Canavaggio, avariations cervantines sur le theme du theatre au theatrex, en Revue des Sciences humaines, XXXVII, 1972, 53-68; tambien Cervantes dramaturgue..., pp. 366-374.

30 Vid. sobre este pasaje, PAUl Lewis SmmH, ela Gran Sultana Catalina de Oviedo...», cit. 
tiempo, todo lo que lleva consigo ese "que os lleve el diablo", pues esa botadura es gracias al trabajo de los cautivos y esas galeras son las que atacan las costas cristianas, las que hacen cautivos en ellas y las que han luchado y luchan contra los cristianos en el Mediterráneo... ${ }^{31}$. Como en Lepanto. $\mathrm{O}$ como las galeras que hicieron preso en 1575 a un soldado llamado Miguel de Cervantes... *

\author{
LUCIANO GaRcta LORENZO \\ C.S.I.C., Madrid
}

${ }^{31}$ Naturalmente, el componente fundamental de Madrigal es la comicidad y ese es el papel que ha jugado a lo largo de la comedia. A ello se han referido habitualmente los estudiosos, incluso, como indicábamos atrás, para catalogar negativamente la obra. Desde otra perspectiva mucho más acertada, vid. el artículo de Canavaggro «Sobre lo cómico en el teatro cervantino...», citado.

* Este trabajo fue leido en las Jornadas sobre teatro clásico, que se celebraron el Almagro (Ciudad Real) los días 5 al 7 de julio de 1993, bajo el título de «Los imperios orientales en el teatro del Siglo de Oro». Doy las gracias a los organizadores de este Encuentro, y especialmente al profesor Felipe Pedraza, por permitirme publicar estas paginas en Anales cervantinos. 